$$
\begin{gathered}
\text { September 28, 2016, GSA - Denver, CO } \\
\text { \# 315-8 }
\end{gathered}
$$

\title{
DISCOVERY OF AN EXPOSED EARLY TRIASSIC NAMAKIER (SALT GLACIER) ON THE WEST FLANK OF THE ONION CREEK DIAPIR IN GRAND COUNTY, UTAH
}

\section{Donald L. Rasmussen}

\author{
Paradox Basin Data \\ 1450 Kay Street, Longmont, CO 80501 \\ paradoxdata@comcast.net
}




\section{Zagros Fold Belt, SE Iran}

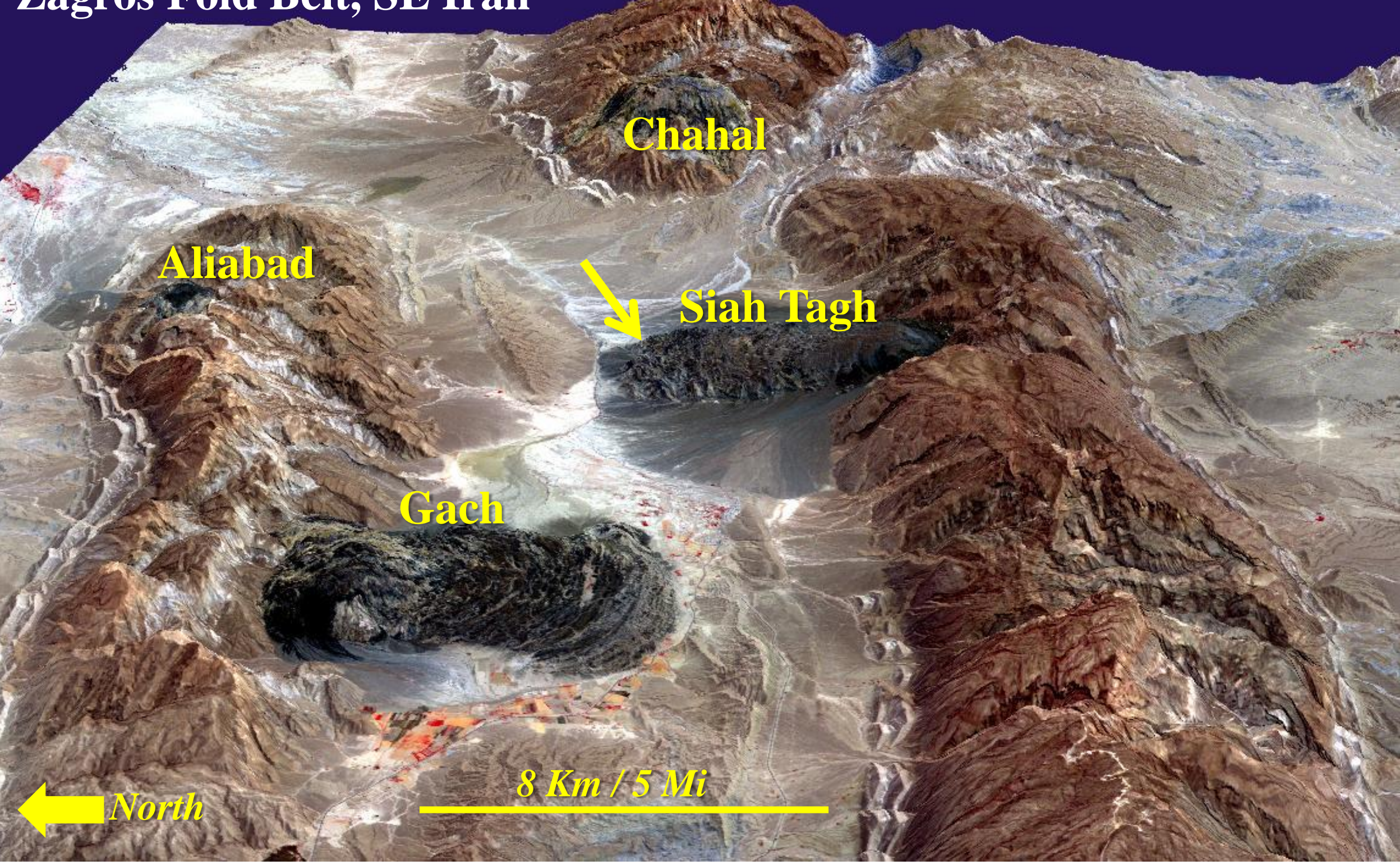

Image courtesy NASA

\section{LOCATION OF THE SIAH TAGH NAMAKIER, IRAN}




\section{Siah Tagh Namakier, Zagros Fold Belt, southeastern Iran}

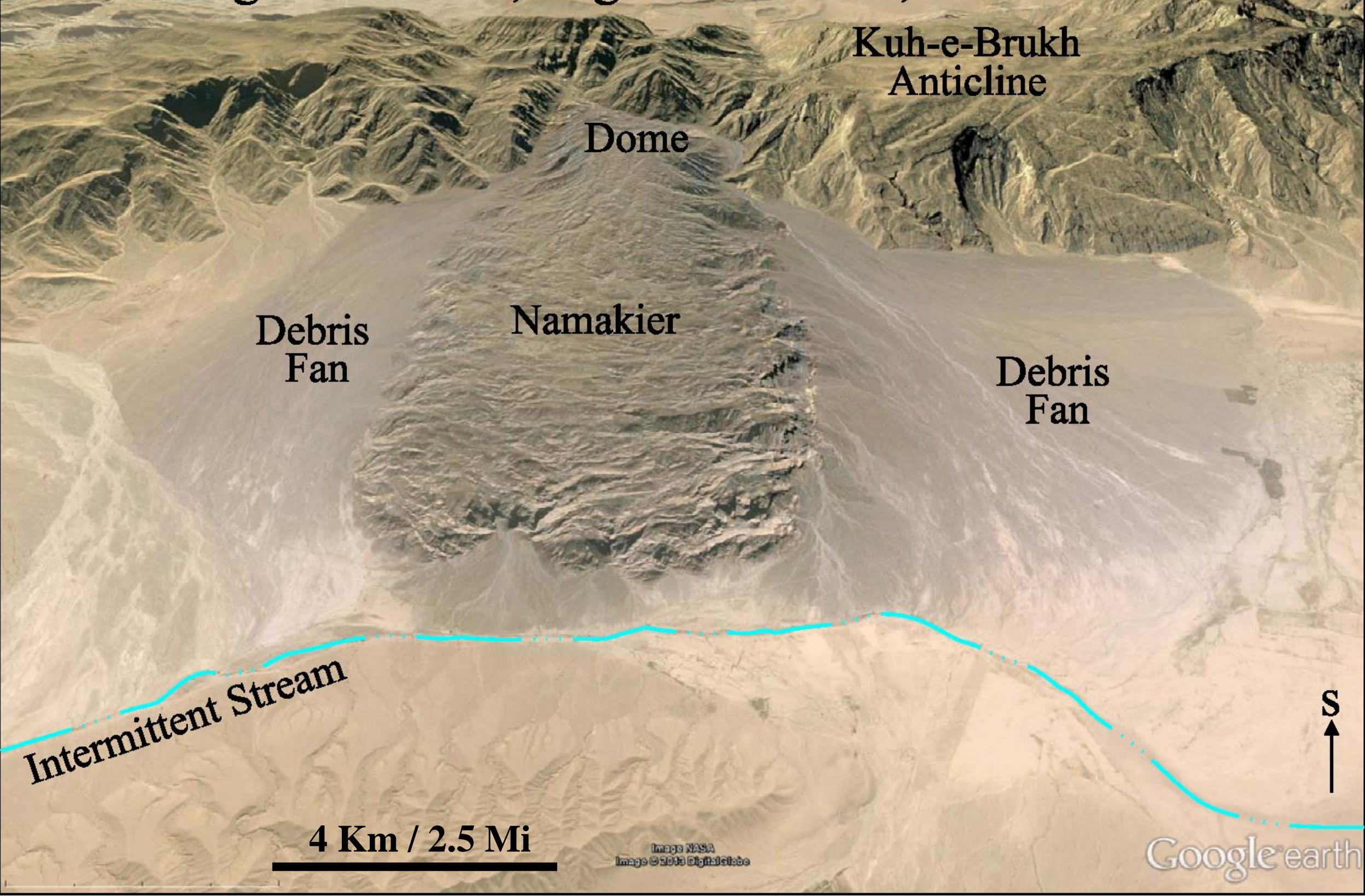

Siah Tagh Namakier is about 4 miles long and terminates near axis of syncline between folds. 


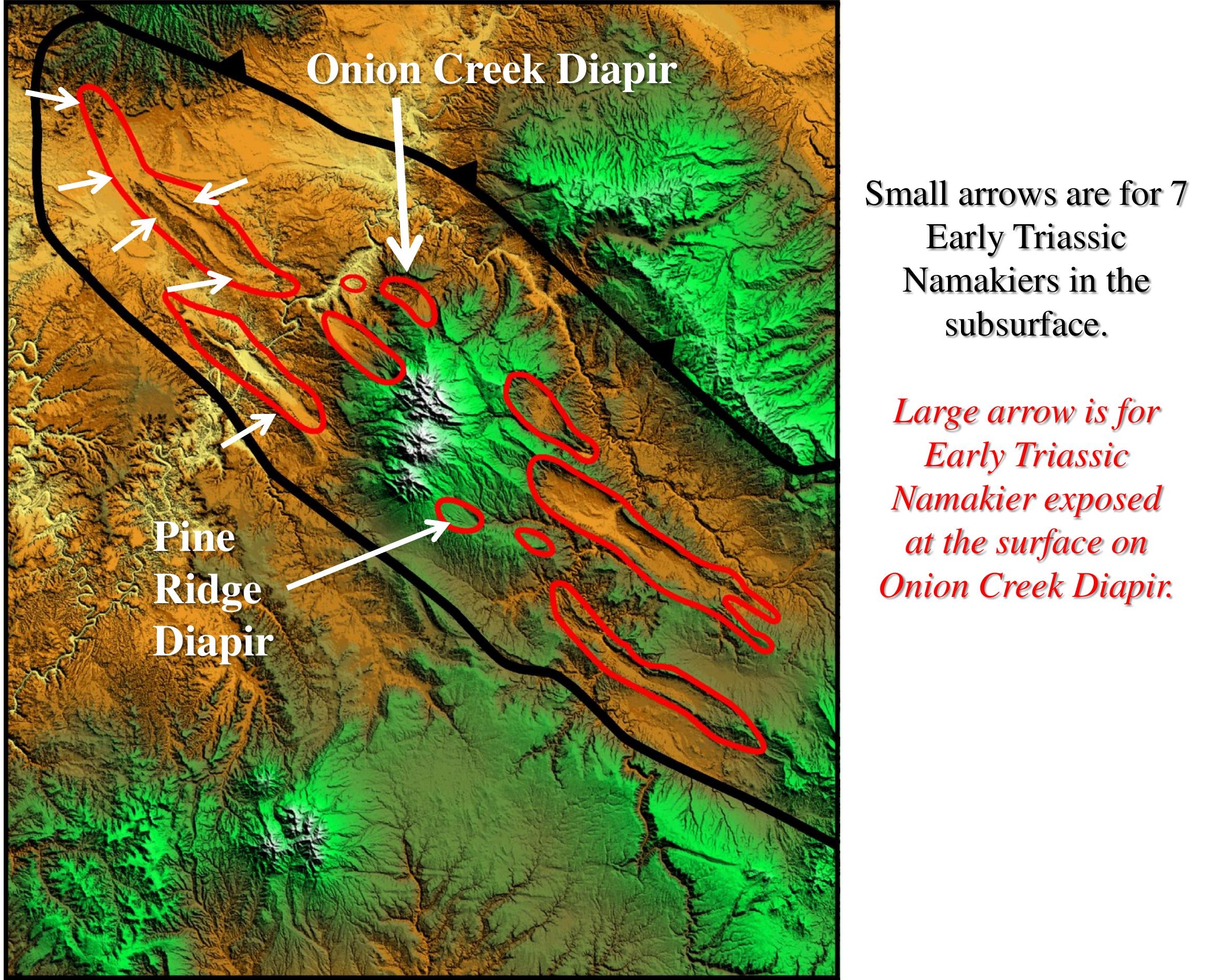


Triassic Moenkopi Fm

Paleogeographic map; Blakey, 2009

Extreme arial climate during Early Triassic.

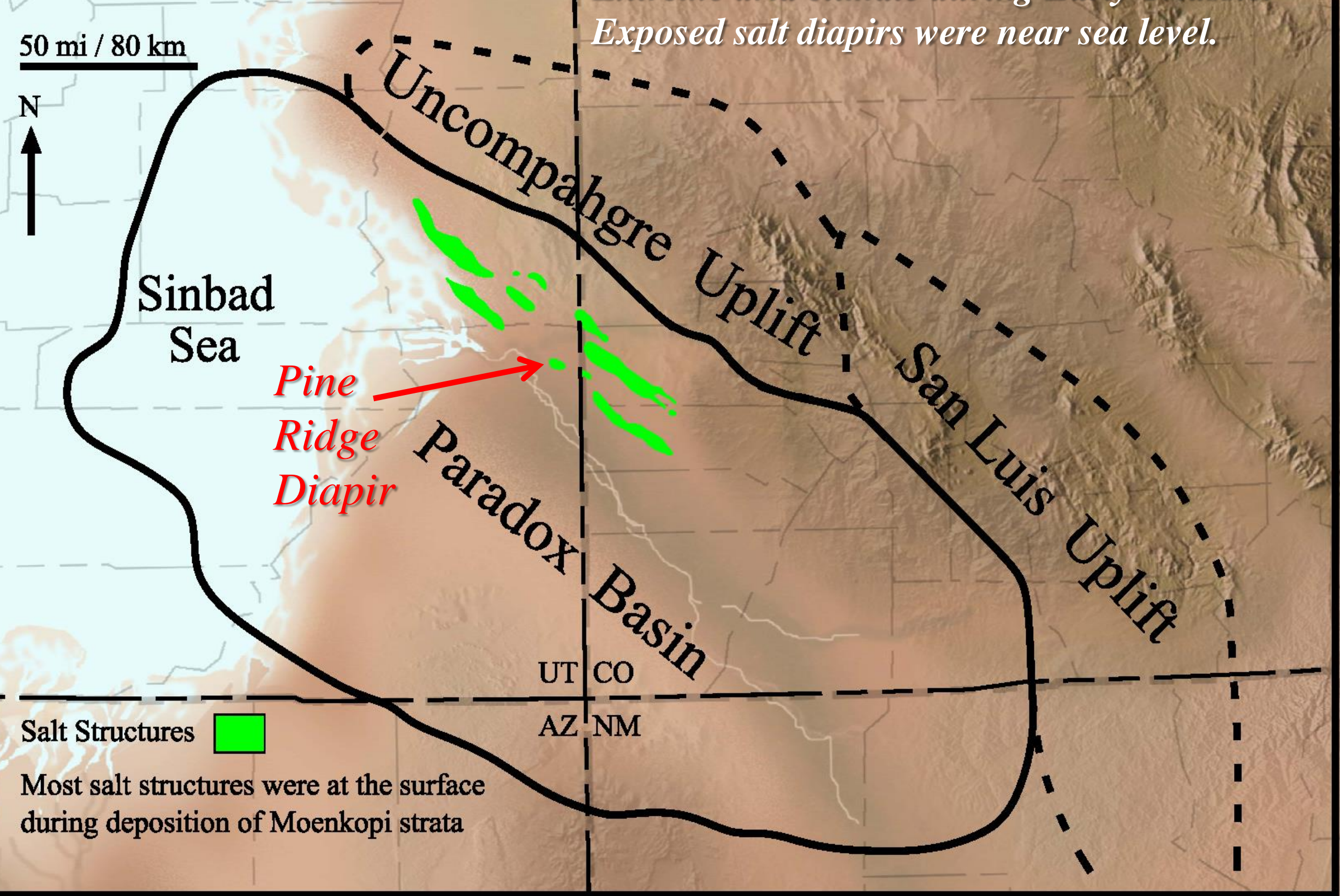




\section{Triassic namakier on flank of Pine Ridge Diapir, San Juan County, Utah}

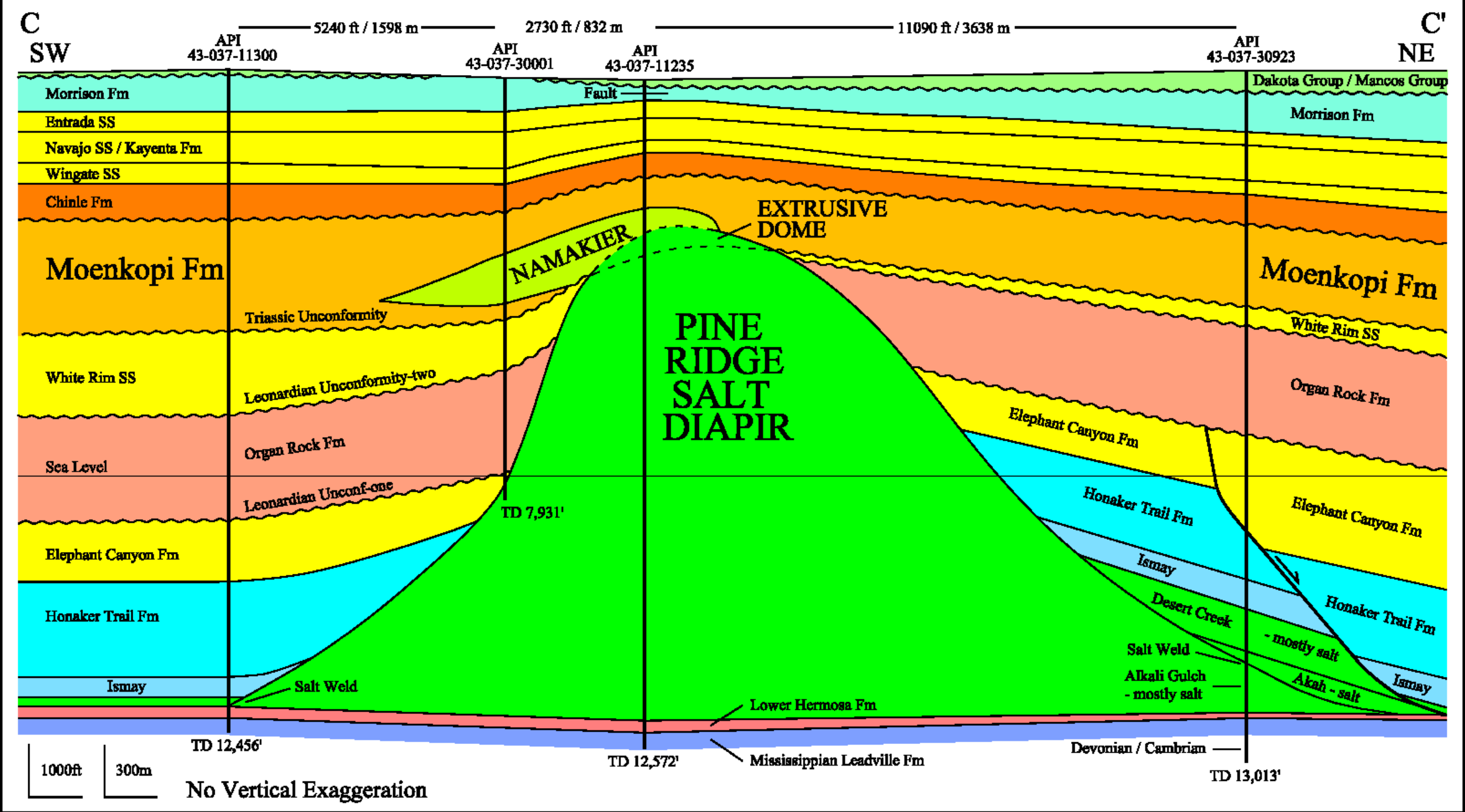

Modified from Rasmussen, 2014 (UGA). 


\section{Triassic namakier on flank of Pine Ridge Diapir, San Juan County, Utah D'}

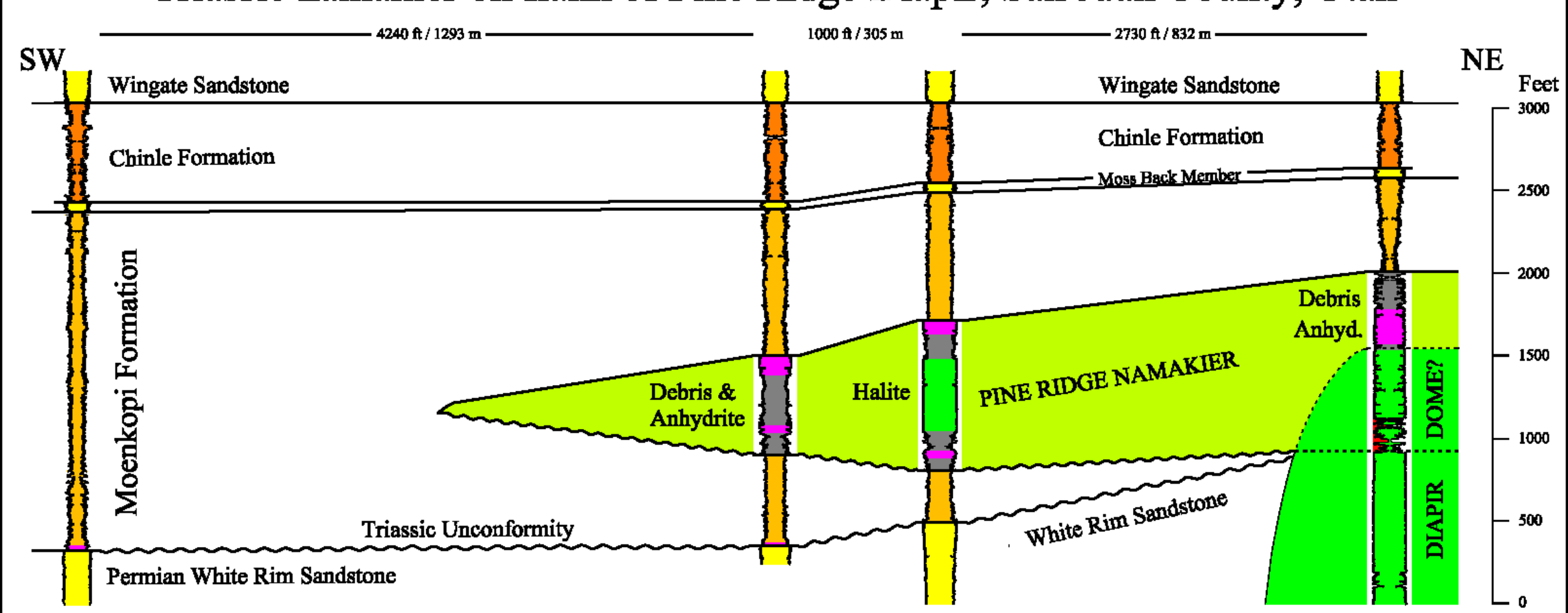

No Vertical Exaggeration

Modified from Rasmussen, 2014 (UGA). 


\section{Hypothetical Paradox Basin subaerial namakiers}

Example A - Young namakier with intact salt core. $\quad$ Example B - Older namakier with dissolution.

EXTRUSIVE

DOME

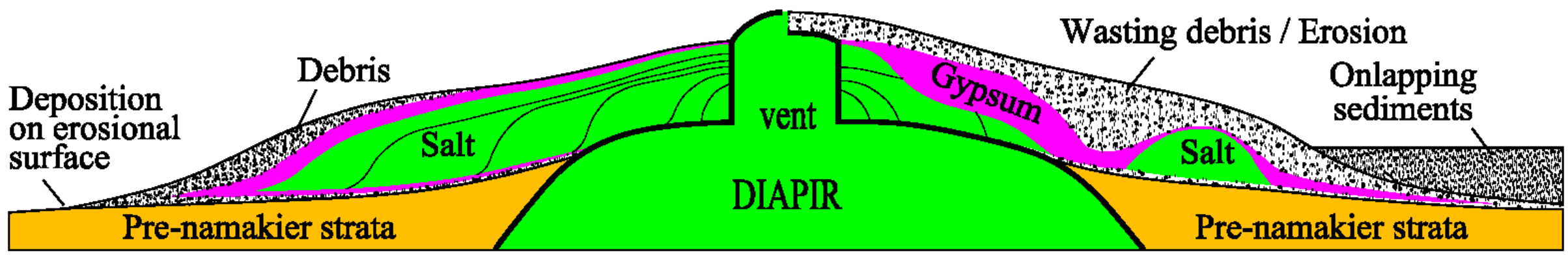

Not drawn to scale

Models are based on extensively studied namakiers in SE Iran, in particular models by Christopher Talbot (Example A), and subsurface well control and data in the Paradox Basin (Example B).

Extrusive dome is a "salt fountain" on a breached diapir.

Modified from Rasmussen, 2014 (UGA). 
Triassic Moenkopi Fm

Paleogeographic map; Blakey, 2009

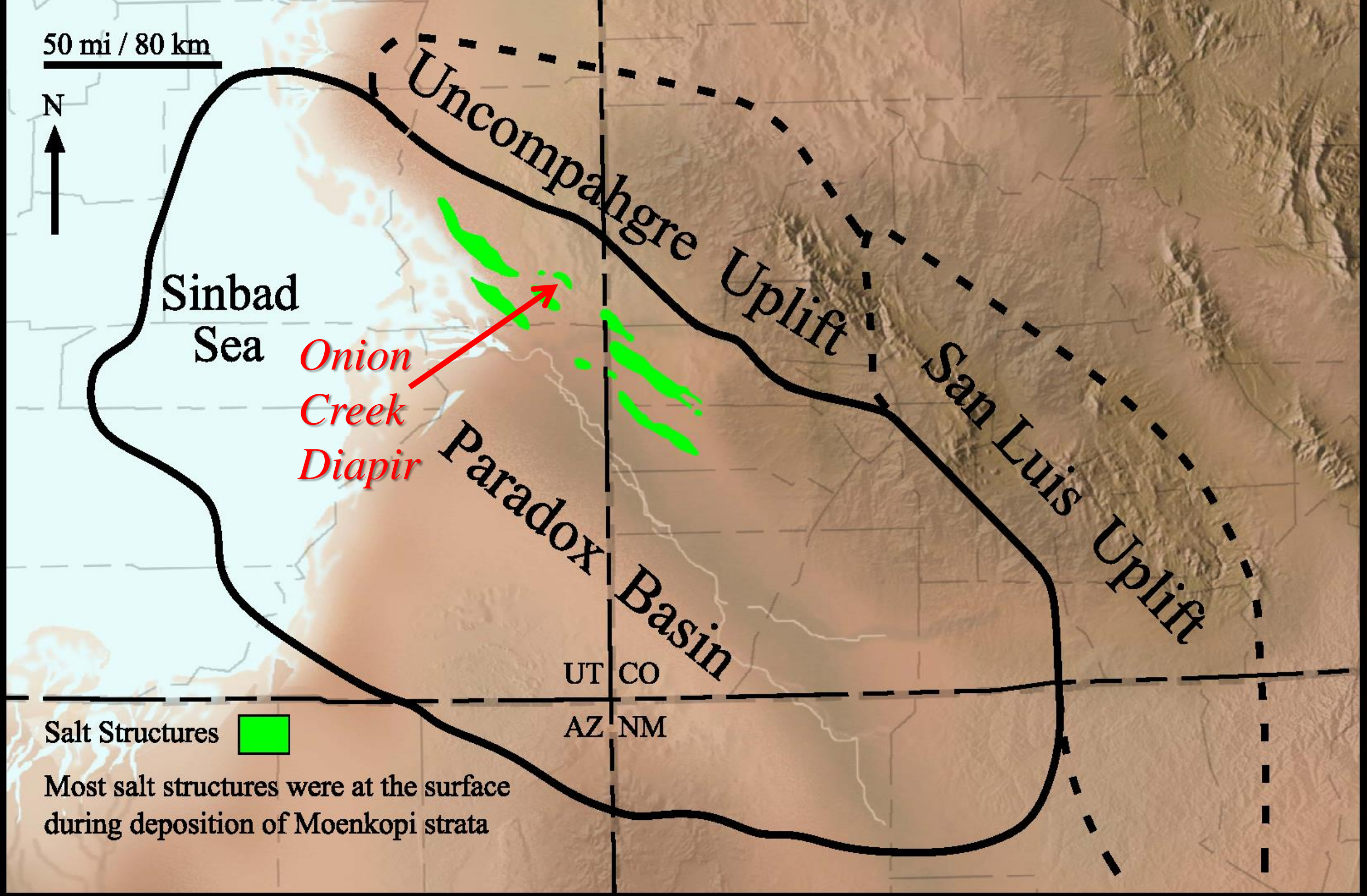




\section{Paradox Basin, SE UT, Onion Creek Extrusion}

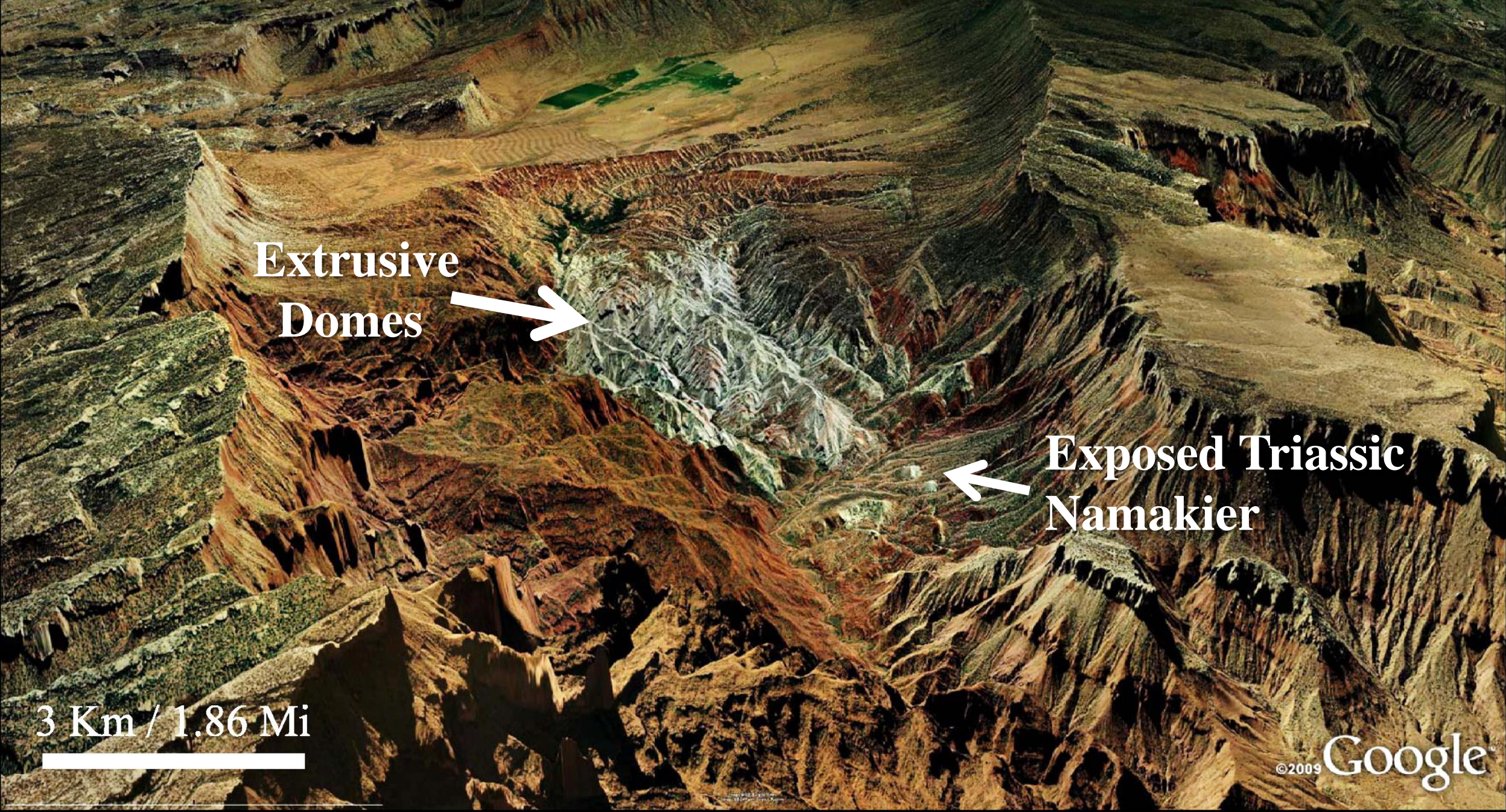

Looking SE into the core of the highly eroded Onion Creek extrusion. Neogene collapse. Vertical exaggeration X3. 


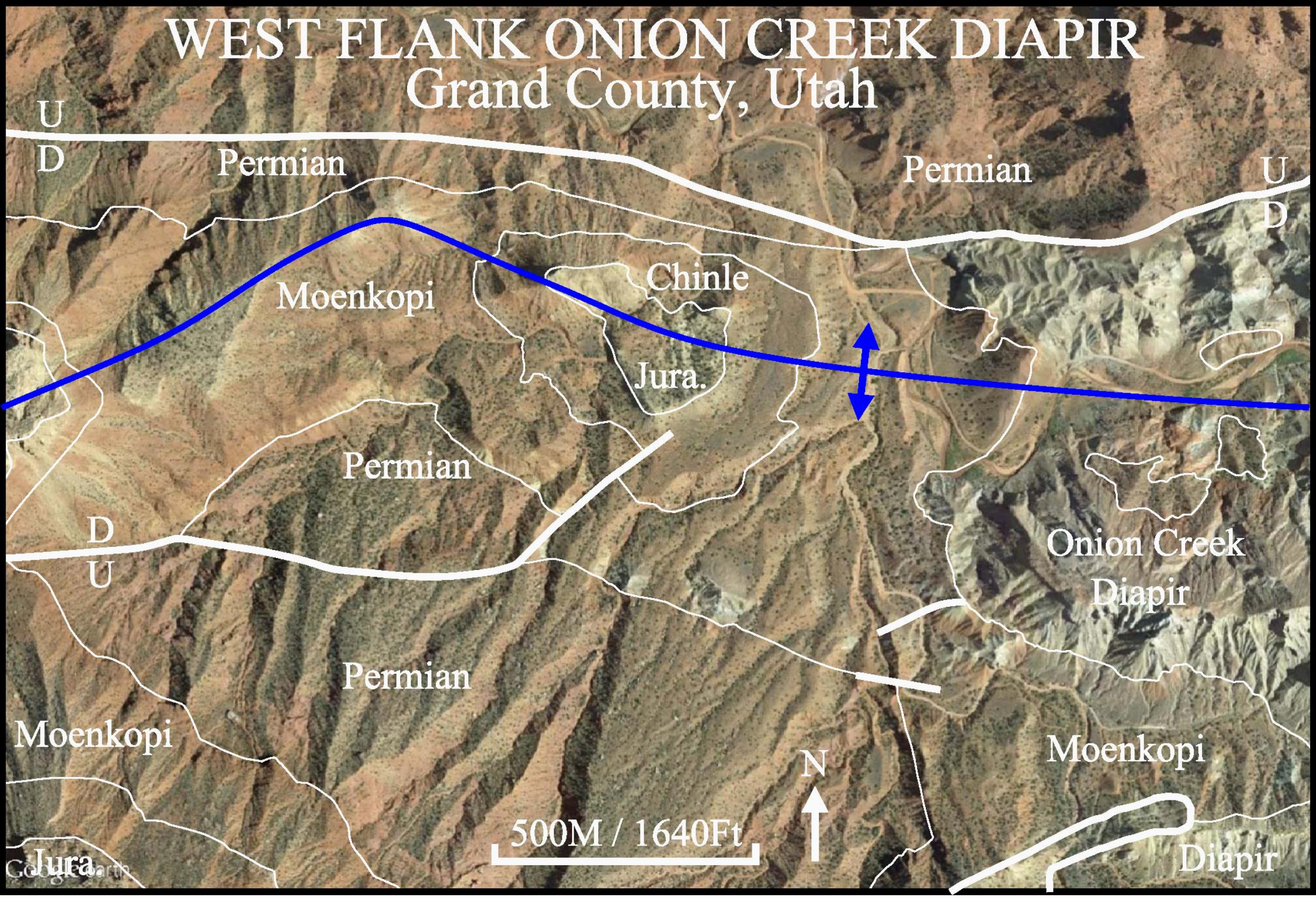

Geology overlay on Google Earth image. Modified from Shoemaker and Doelling. 


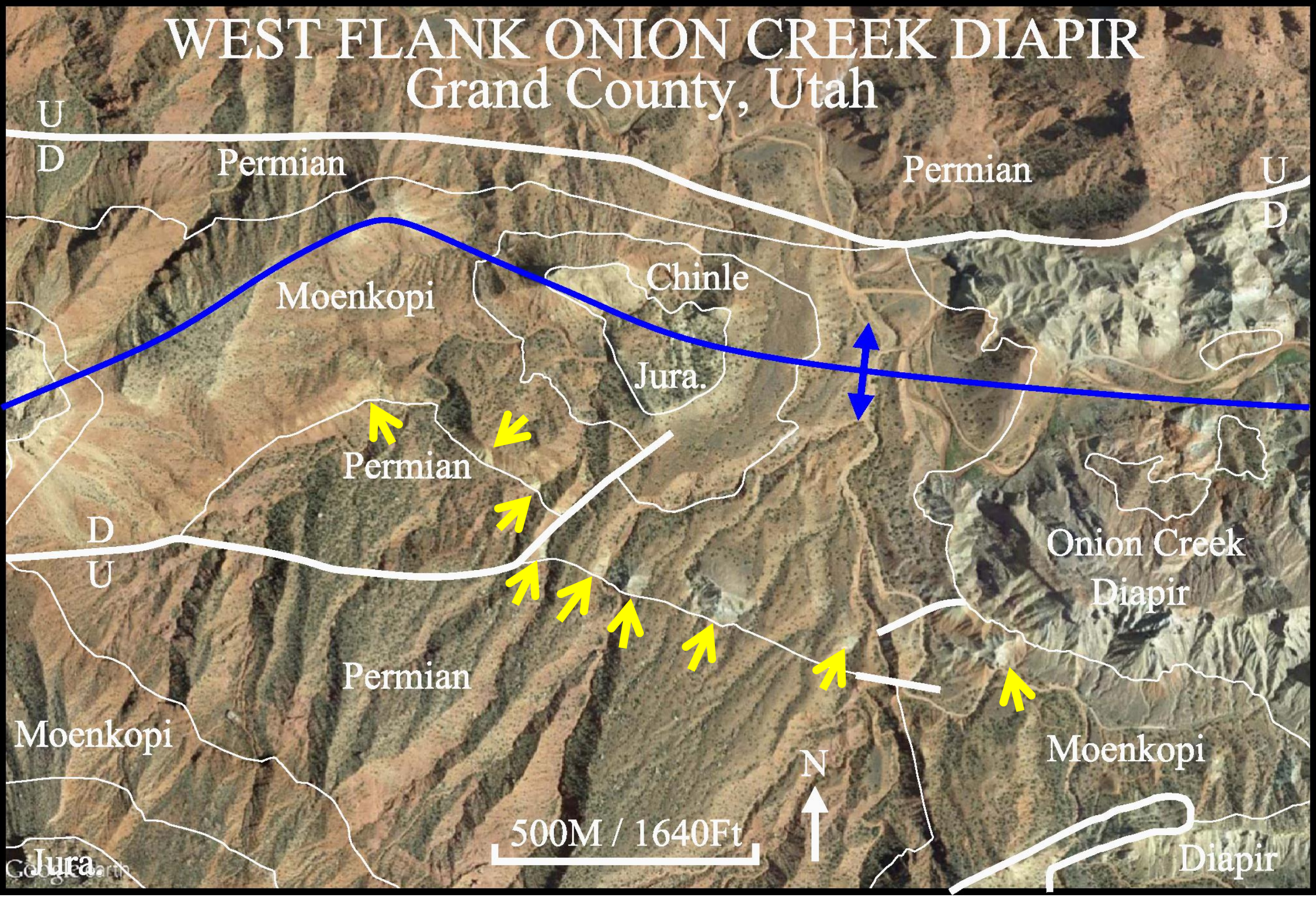

Geology overlay on Google Earth image. Modified from Shoemaker and Doelling. Arrows indicate Namakier outcrops. 
U Grand County, Utah

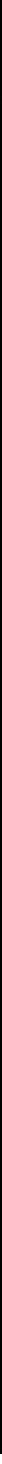

West Onion Creek namakier trend exposed in outcrops along south flank of syncline. 


\section{ONION CREEK EARLY TRIASSIC NAMAKIER Grand County, Utah}

NAMAKIER OUTCROP TREND

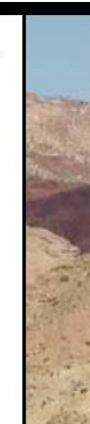




\section{WEST ONION CREEK EARLY TRIASSIC NAMAKIER Drone photo 8/21/16 - looking east.}

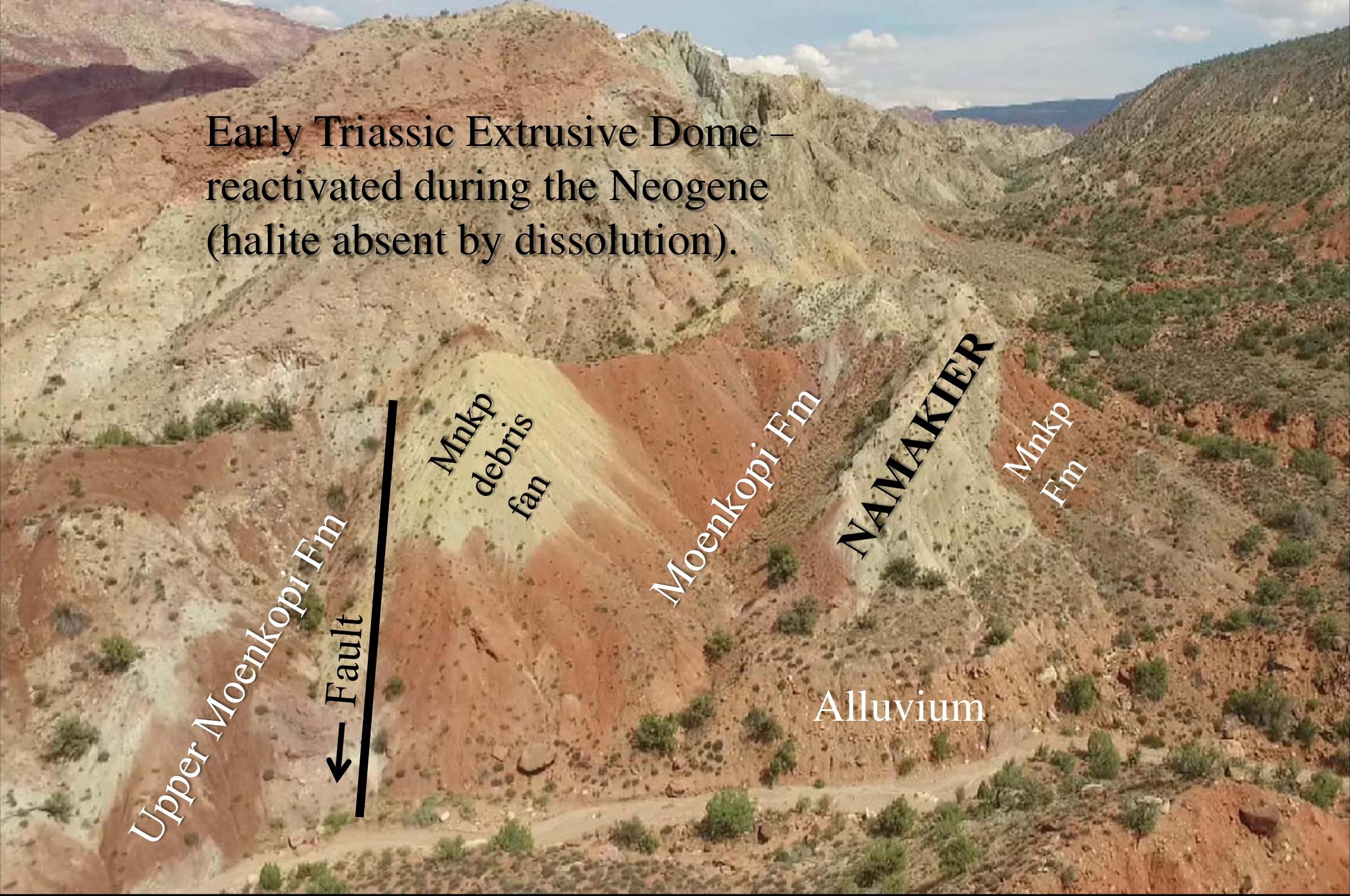




\section{WEST ONION CREEK EARLY TRIASSIC NAMAKIER}

Drone photo $5 / 5 / 16$ - looking west.

\section{NAMAKIER}

Moenkopi strata underlying namakier

Gypsum after halite dissolution

Interbedded and onlapping Moenkopi strata 
WEST ONION CREEK NAMAKIER; photo 5/5/16 - looking northeast

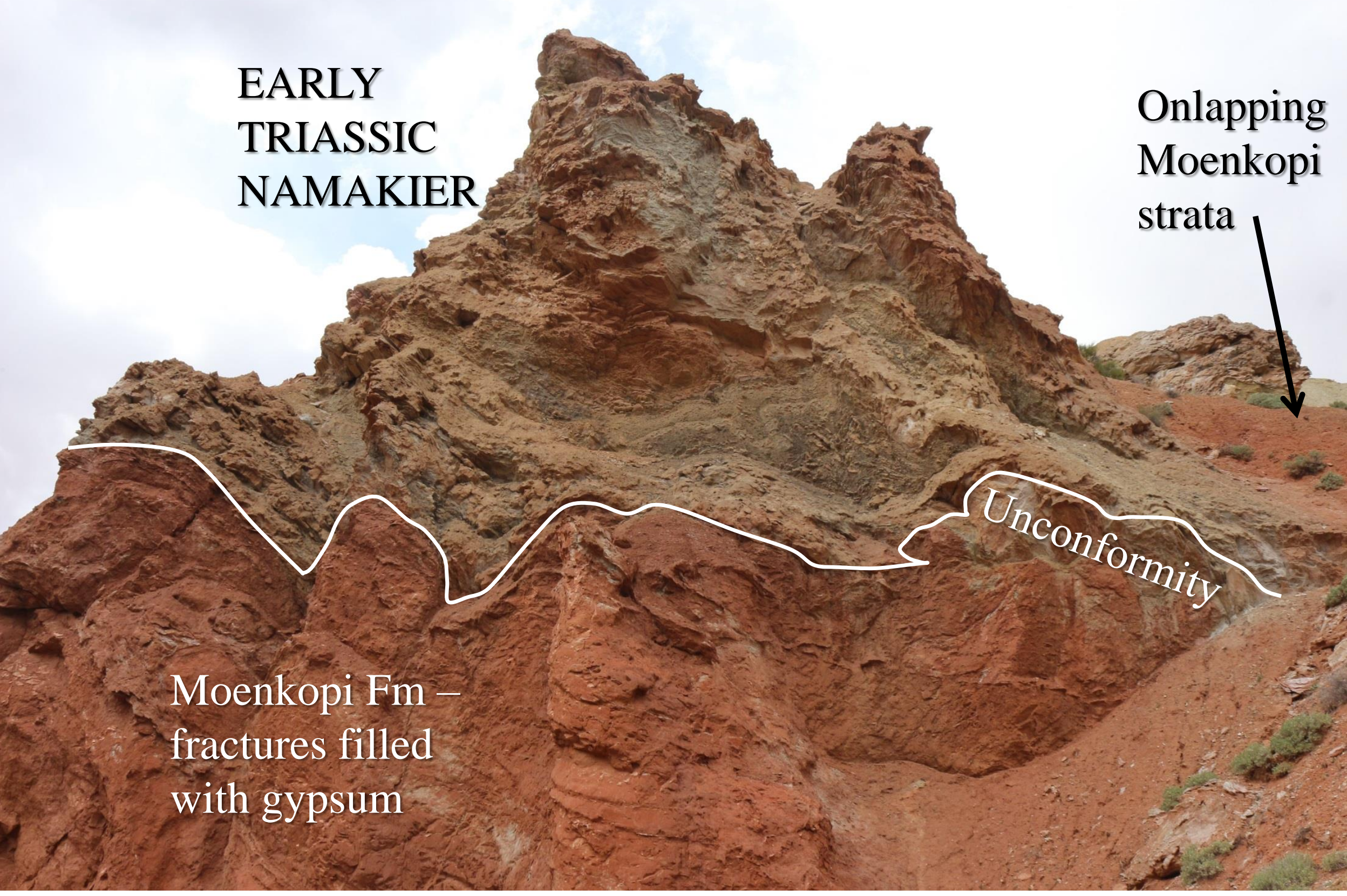




\section{WEST ONION CREEK NAMAKIER}

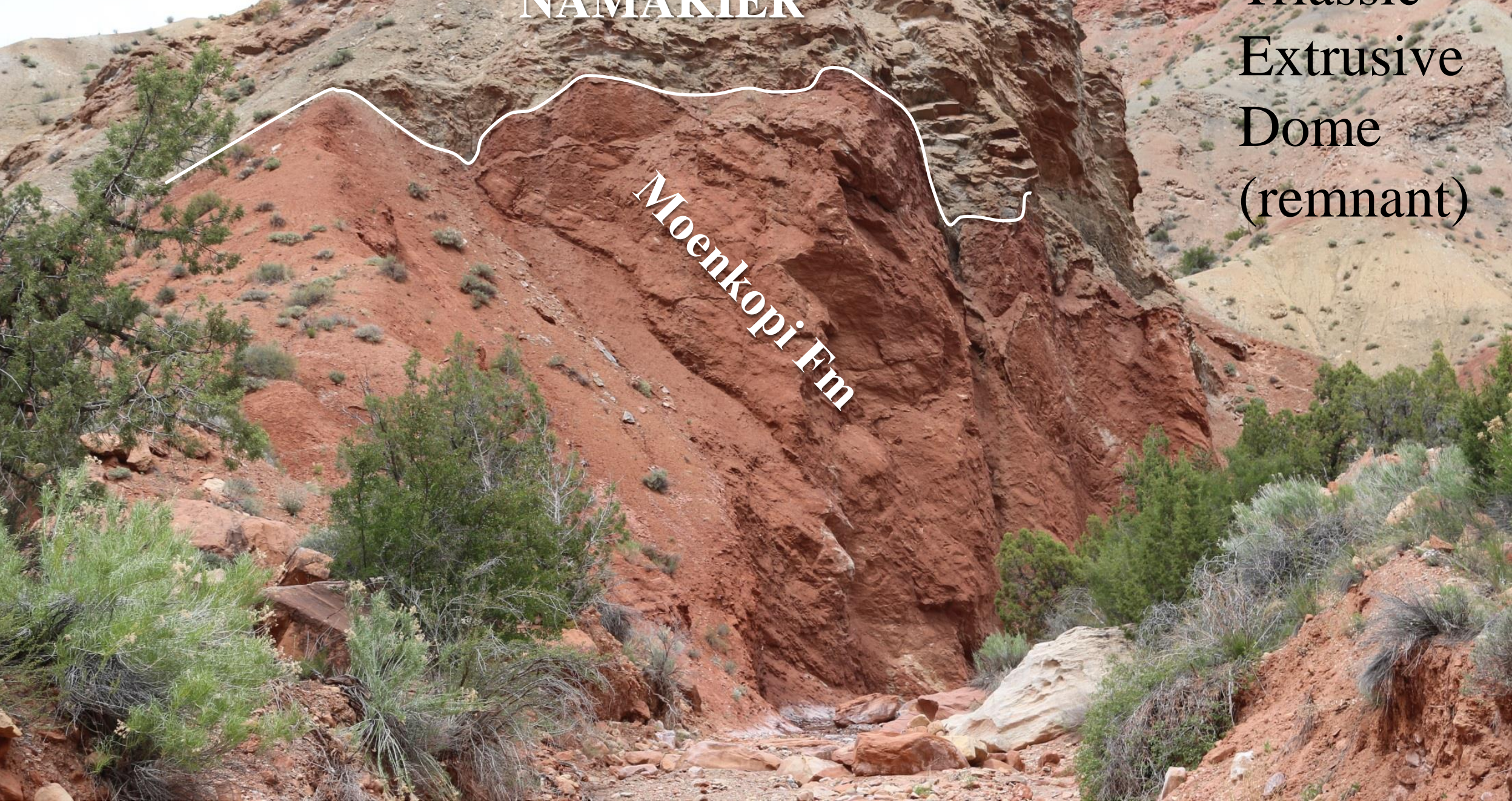

\section{Another view of the Early Triassic Namakier unconformably on deformed Moenkopi strata.}




\section{ONION CREEK EARLY TRIASSIC NAMAKIER Grand County, Utah}

NAMAKIER OUTCROP TREND

\section{.

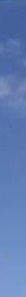
PHOTO

$500 \mathrm{M} / 1640 \mathrm{Ft}$ T

TRIASSIC EXTRUSIVE DOME 


\section{WEST ONION CREEK EARLY TRIASSIC NAMAKIER}

Photo 4/29/11 - looking north.

Gypsum after halite dissolution

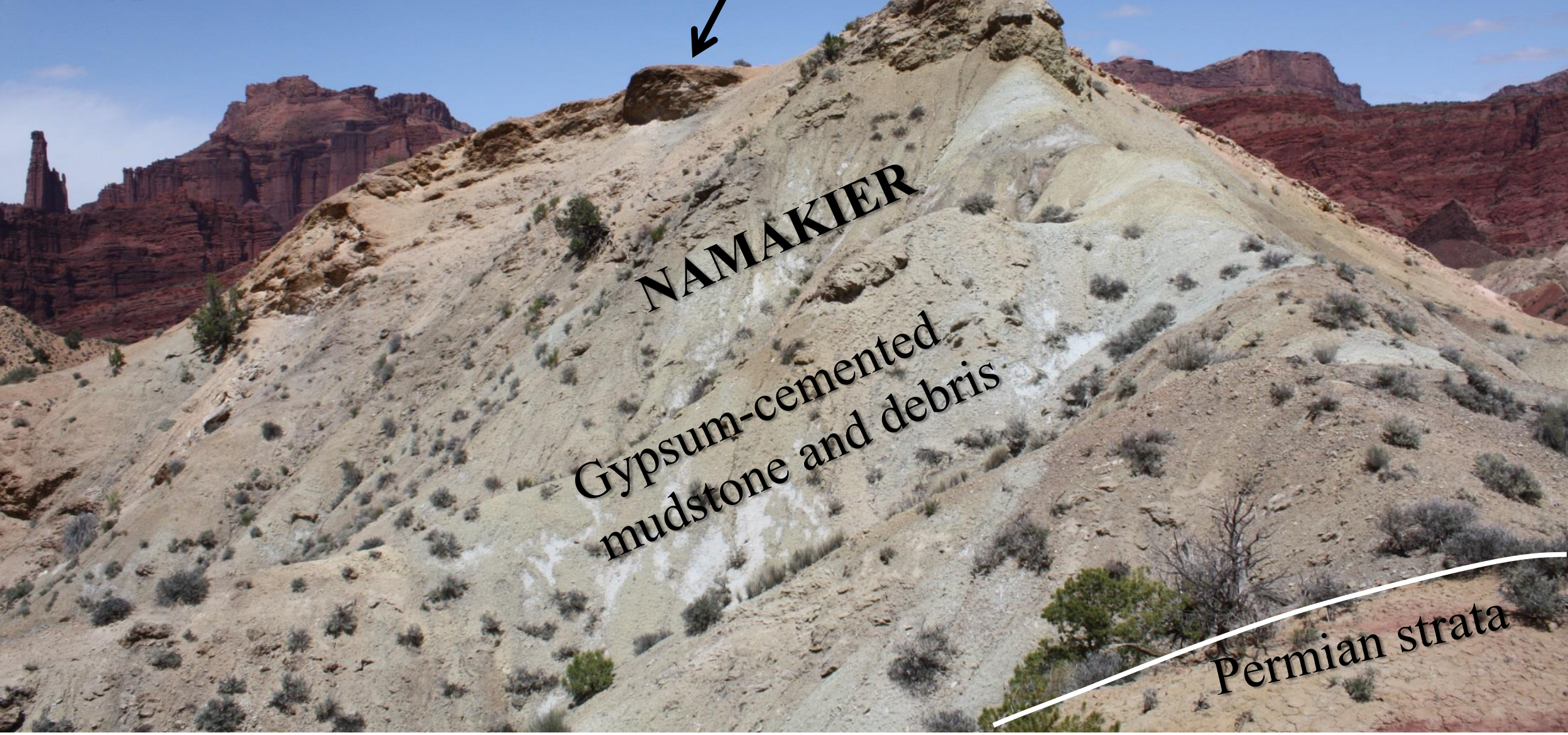

Namakier debris and gypsum approximately one-half mile west of extrusive dome; unconformably on folded and eroded Permian strata. 


\section{ONION CREEK EARLY TRIASSIC NAMAKIER Grand County, Utah}

NAMAKIER OUTCROP TREND
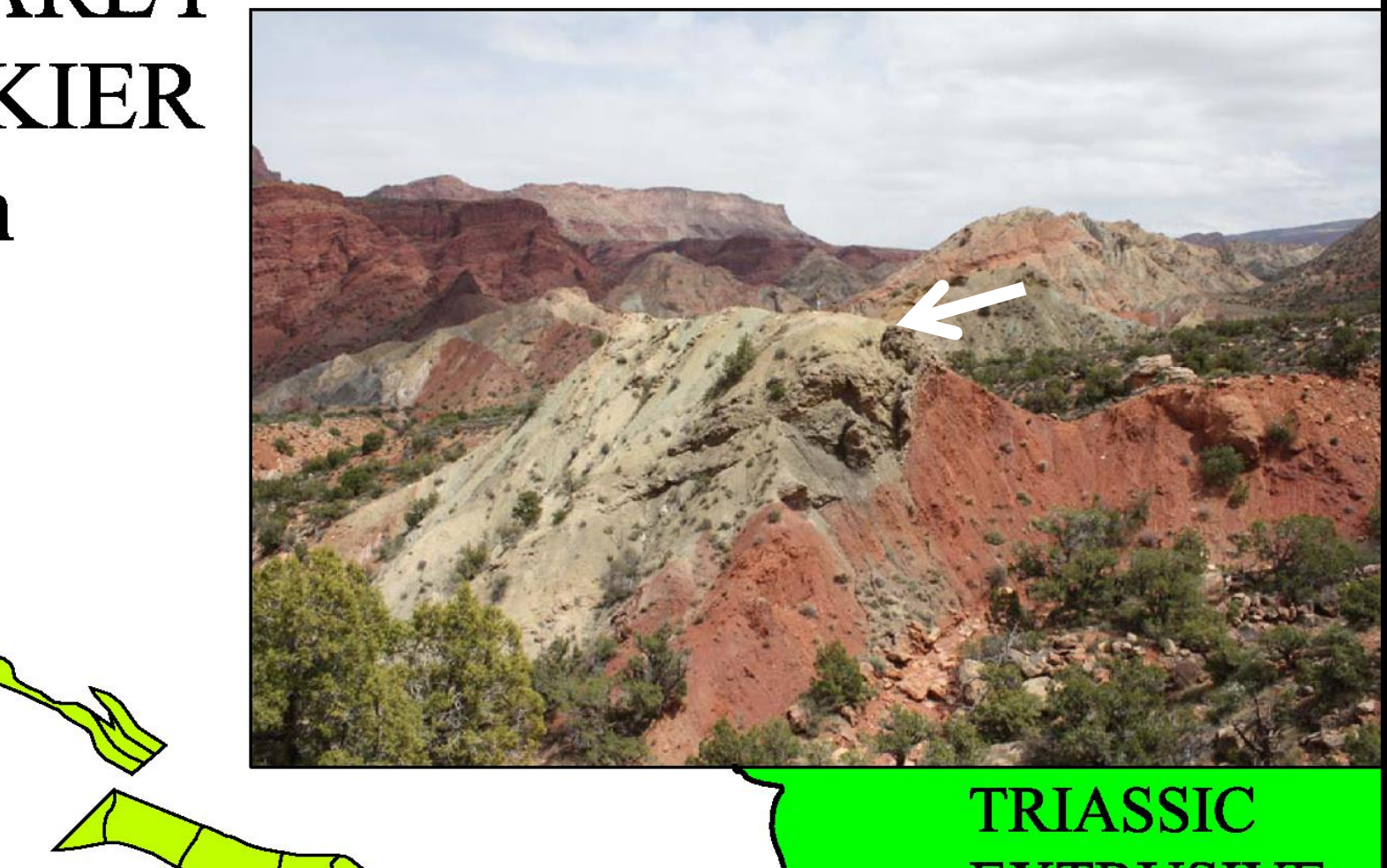

PHOTO
TRIASSIC

EXTRUSIVE

$500 \mathrm{M} / 1640 \mathrm{Ft}$ 个 


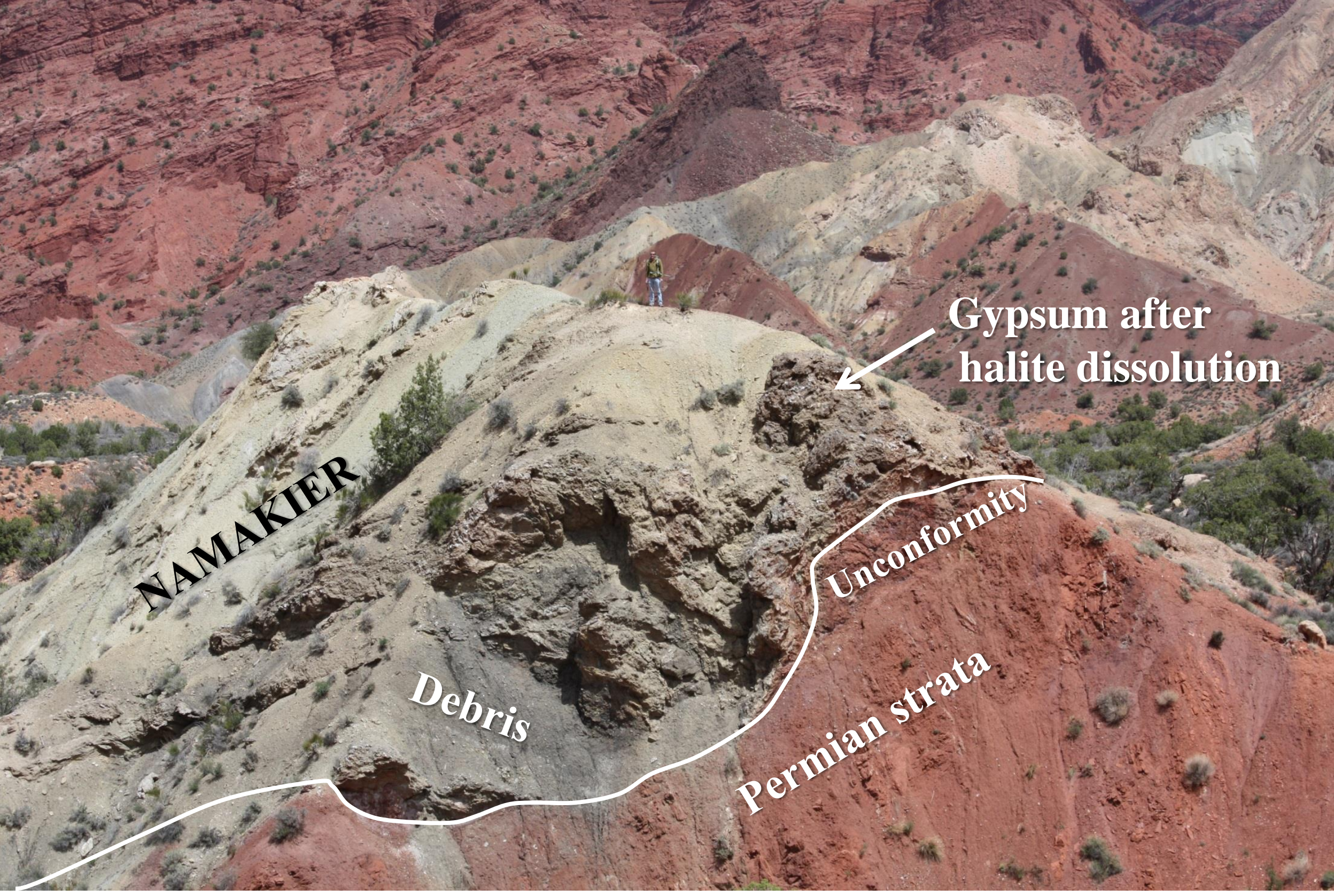

Namakier gypsum (after halite) and debris unconformably on Permian strata. 


\section{WEST ONION CREEK EARLY TRIASSIC NAMAKIER}

\section{Photo 4/29/11 - looking southeast}




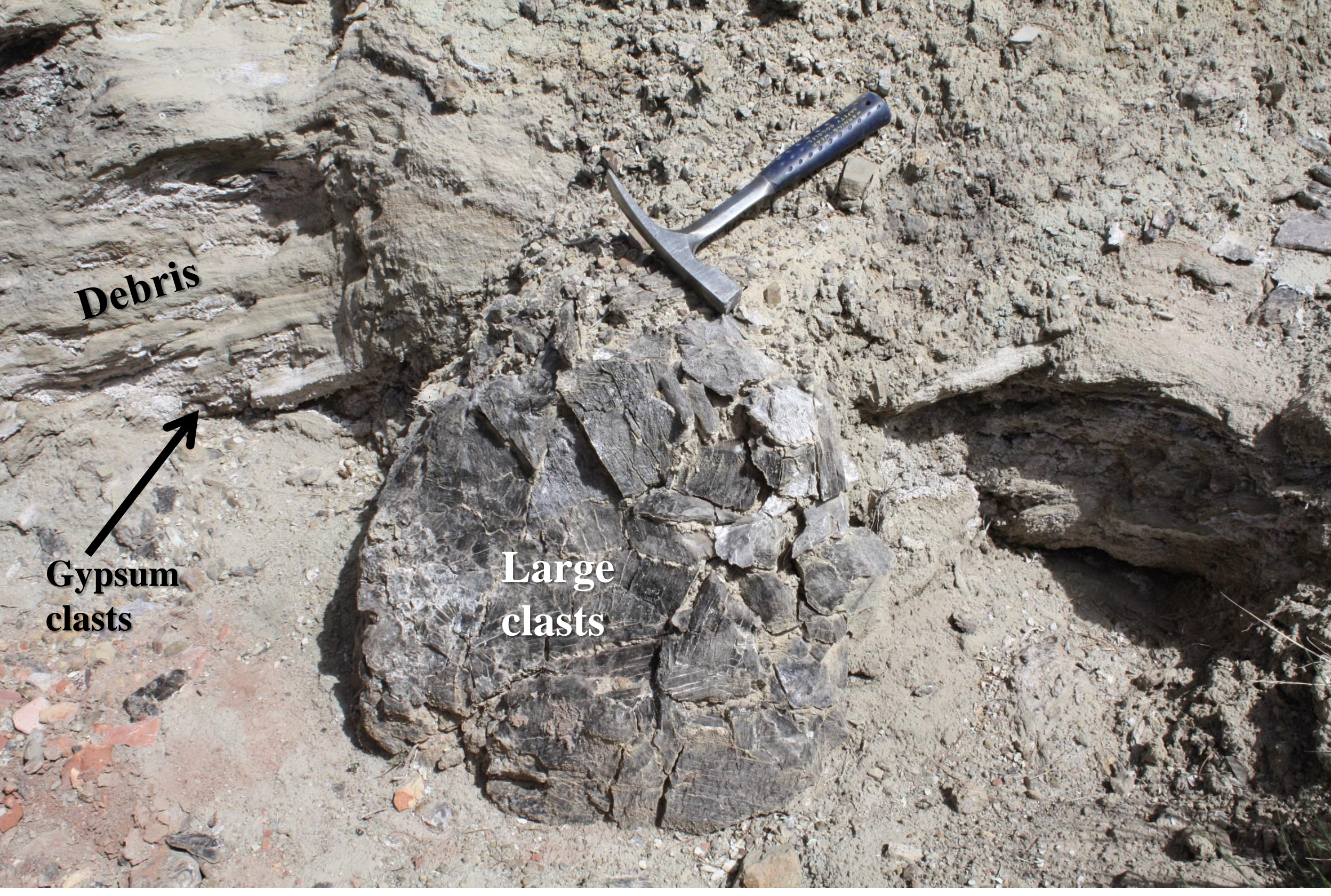

Cemented gypsum clasts within fan debris of the West Onion Creek Namakier. Photo 4/29/11 


\section{ONION CREEK EARLY TRIASSIC NAMAKIER Grand County, Utah}

NAMAKIER OUTCROP TREND

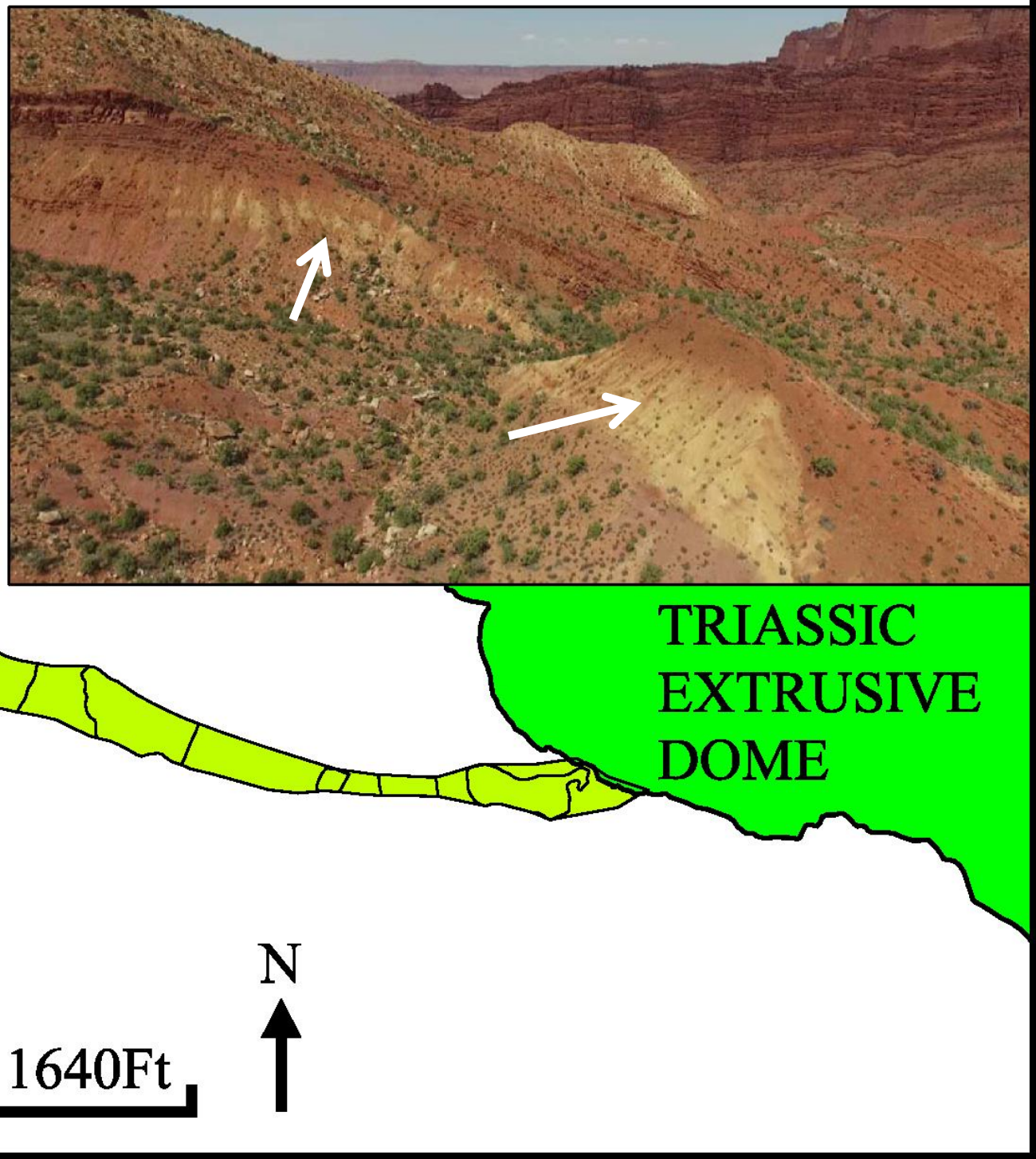




\section{WEST ONION CREEK EARLY TRIASSIC NAMKIER}

\section{Drone photo 8/21/16 - looking northwest}

Moenkopi

strata

Permian strata
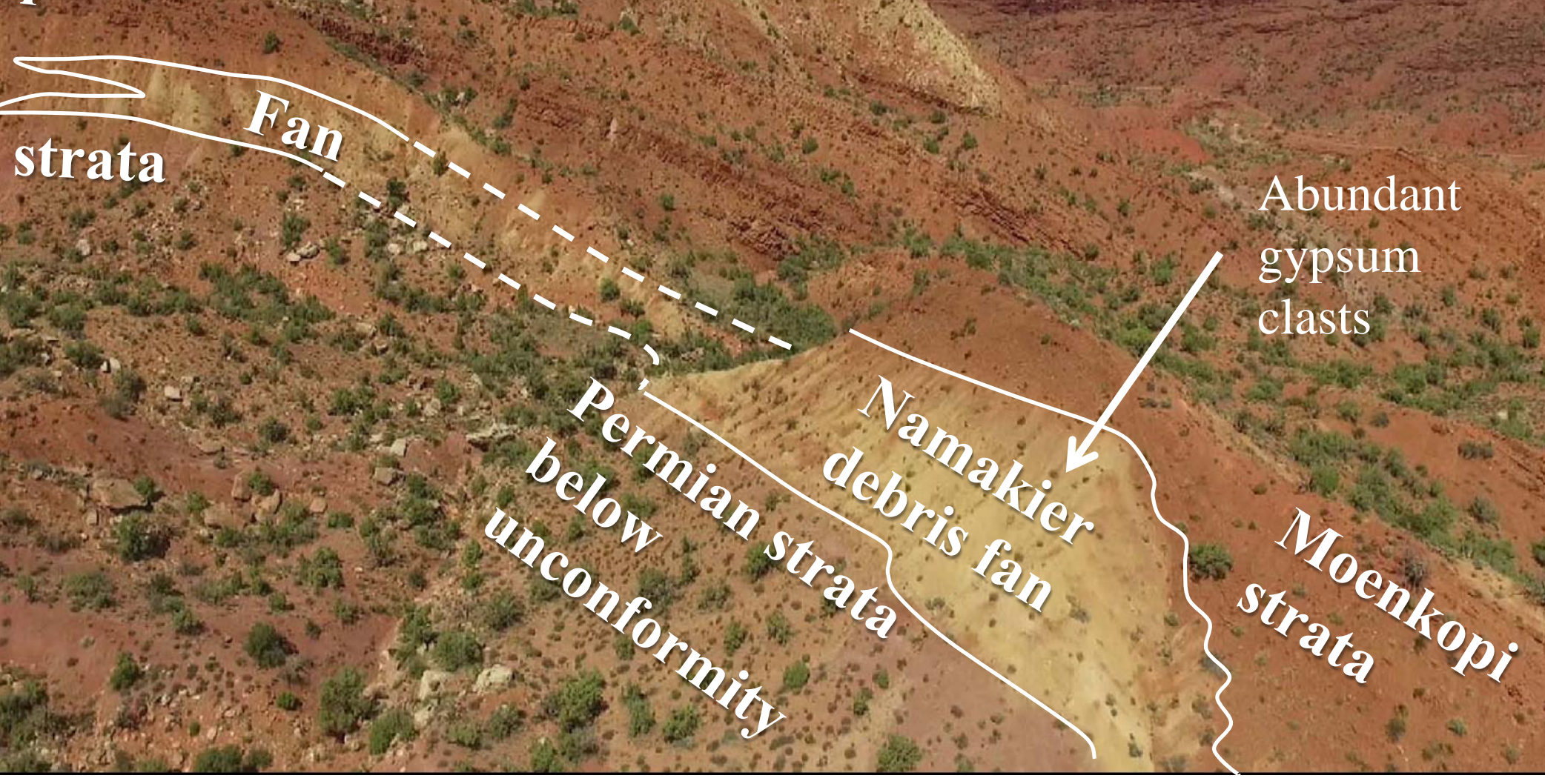

Distal debris fan of the Namakier interbedded with E. Triassic basal Moenkopi strata. 


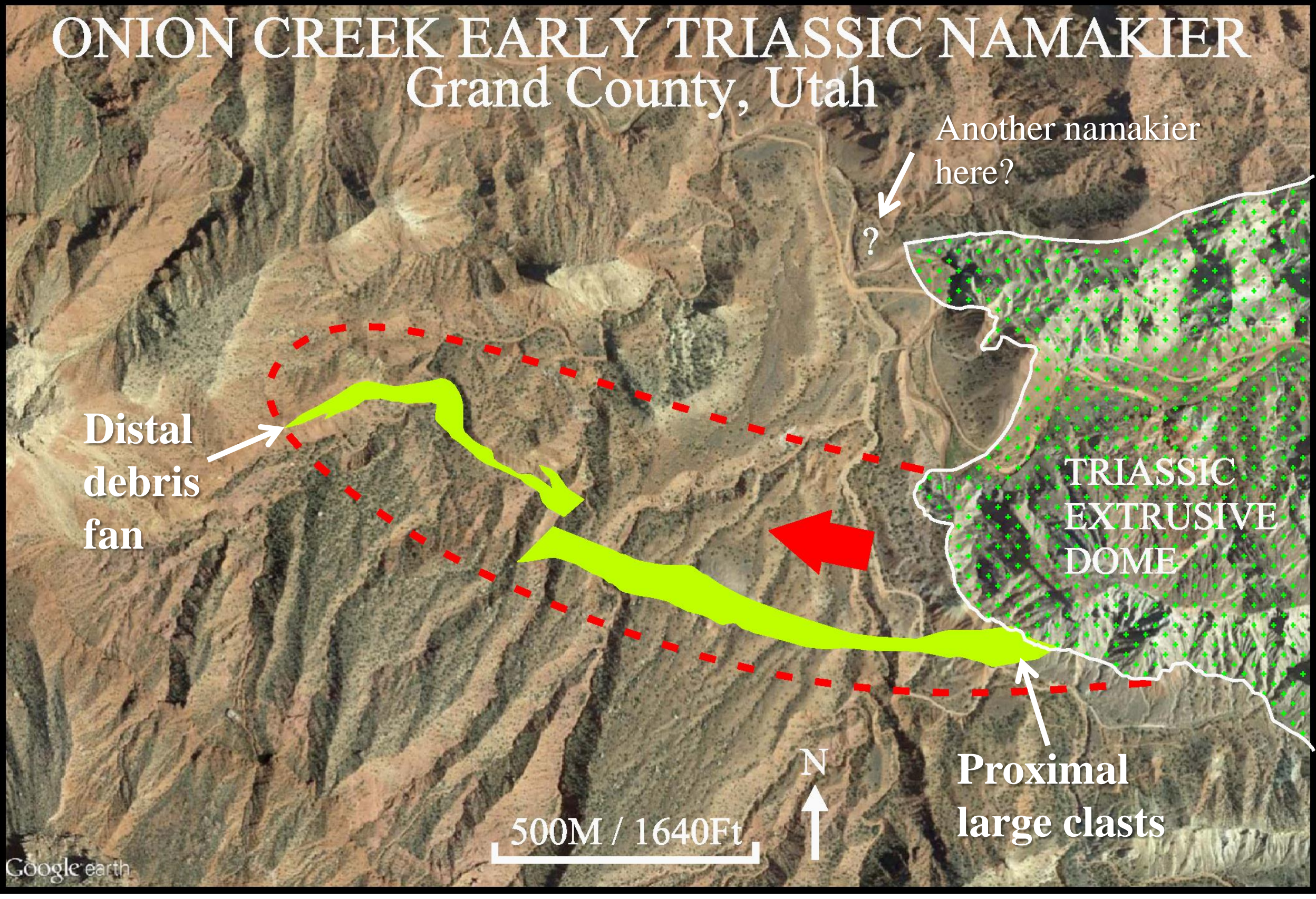

Postulated outline (red) for the West Onion Creek Namakier during the Early Triassic. 


\section{VIDEO: RASMUSSEN_GSA_DJI_0083_NAMAKIER.MP4}

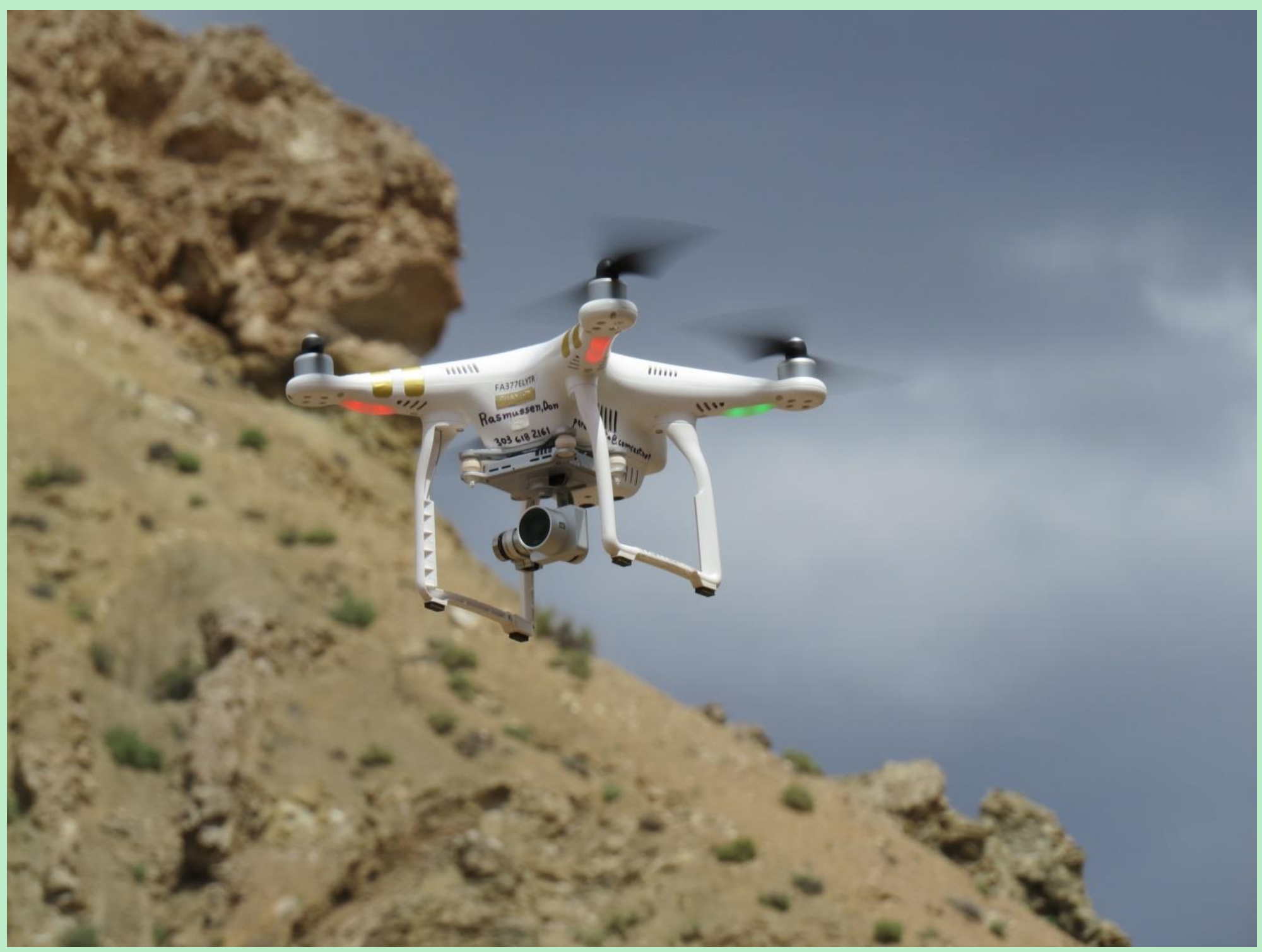

DJI Phantom 3 Professional Drone - photo by Kirk Branson 